\title{
LOS ELOGIOS DE FELIPE V DE 1779
}

\author{
Marina Alfonso Mola \\ Carlos Martínez Shaw \\ Universidad Nacional de Educación a Distancia
}

\section{$\underline{R E S U M E N}$}

Se analiza la inagen de Felipe $\mathrm{V}$ a partir de dos obras ganadoras del premio a la elocuencia, convocado por la Real Academia Española en 1779.

Palabras claves: Imagen de Felipe V, España, siglo XVIII.

\section{ABSTRACT}

This article explores the Felipe V's Image by examining two prizewinner's plays given according to their eloquence by Real Academia Española in 1779.

Keywords: Felipe V's Image, Spain, XVIII ${ }^{\text {th }}$ century.

La muerte de los soberanos originaba en el Antiguo Régimen una serie de productos literarios destinados a honrar su memoria. Los más usuales eran las oraciones fúnebres y los elogios póstumos. Las primeras se pronunciaban en el momento de las exequias que las diversas instituciones (y en primer lugar, las distintas ciudades) ordenaban celebrar en catedrales, iglesias conventos y monasterios a todo lo largo de la geografía española. Los últimos podían escribirse más tarde y publicarse en boletines o periódicos o como opúsculos independientes, o bien declamarse en multitud de lugares, como podían ser las academias, los centros de enseñanza y de investigación o las sociedades patrióticas. Tales textos venían a ser una laudatio del monarca desaparecido que solía organizarse de modo cronológico siguiendo los hitos de su biografia. En todo caso, todos ellos constituyen si no fuentes objetivas sobre la obra realizada por los soberanos, si al menos testimonios, lastrados ciertamente por su tono obligadamente hagiográfico, de la consideración que su persona y su actuación merecían a los ojos de los coetáneos'.

\footnotetext{
'ALBIAC, M. D.: "La transfiguration d'une époque: les oraison funèbres de Charles III", en CHASTAGNERET, G. y DUFOUR, G. (dirs.): Le règne de Charles III. Le despotisme éclairé en Espagne, París, 1994, pp. 213-237; IMPARATO-PRIEUR, S.: "Charles III dans ses oraisons funèbres: une forme de biographie", en SOUBEYROUX, J.: La Biographie dans le monde hispaniqtie, SaintEtienne, 2000, pp. 123-142.
} 
Las oraciones fúnebres y los elogios de los soberanos españoles fueron tan numerosos que constituyen por sí solos una soberbia cantera para los investigadores, que en efecto se han sentido atraídos con frecuencia por esta abundante documentación. Así, la muerte de Felipe $V$ suscitó una gran proliferación de oraciones pronunciadas en las solemnes exequias que se multiplicaron por toda España y que corrieron a cargo de las ciudades y de otras diversas instituciones, entre las que se publicaron, junto a las de numerosas poblaciones, al menos las organizadas por las Universidades de Alcalá, de Salamanca, de Valladolid y de Zaragoza, el Colegio de San Telmo de Sevilla, el Seminario de Nobles de Madrid, la Regia Sociedad Médica de Sevilla, el Tribunal de la Casa de la Contratación de Cádiz, así como por la Archicofradía del Sacramento, la Hermandad del Refugio y la Congregación de la Virgen de la Esperanza de Madrid².

Nosotros no vamos a ocuparnos, sin embargo, de las oraciones fúnebres que siguieron a la muerte del monarca, sino tan sólo de dos textos tardíos que se publicaron como resultado de la concesión del primer premio de elocuencia convocado por la Real Academia Española en 1777. En efecto, aunque la Real Academia había tenido ya el propósito de incluir entre sus actividades la celebración de este tipo de concursos en 1755, fecha en la que se elaboró un plan "para promover y adelantar la verdadera elocuencia", la primera convocatoria no se haría hasta setiembre de aquel año ${ }^{3}$.

Así, las Actas de este año nos dan cuenta de las circunstancias de la convocatoria del certamen:

"Se trató en esta Academia del repartimiento de los Premios de Elocuencia y Poesía; se acordó que se escriba al Señor Conde de Floridablanca para que participe al Rey la determinación de la Academia, avisándole los asuntos que se han escogido, que son para la elocuencia en prosa el elogio del Señor Felipe V, y para la poesía la destrucción de las naves de Hernán Cortés en un romance heroico (aunque al margen se rectifica el metro, sustituyendo el romance por las octavas) ${ }^{\text {sdid. }}$.

Naturalmente, la elección del tema para el premio de elocuencia no tenía otro motivo que el de inaugurar los certámenes con la exaltación del soberano que había fundado la Real Academia y que además era padre del monarca reinante. $Y$ así, naturalmente, fue entendido por la Real Orden comunicada unos días más tarde por Floridablanca y leída a los académicos:

\footnotetext{
${ }^{2}$ Citamos tan sólo algunas de las recogidas por AGUILAR PIÑR, F.: Bibliografía de autores espanoles del siglo XVII, Madrid, 1981-1999 (9 volúmenes).

${ }^{3}$ Sobre el plan de 1755, cf. ZAMORA VICENTE, A.: La Real Academia Española, Madrid, 1999, pp. 392-393.

${ }^{4}$ de la Real Academia Española (ARAE). Actas, 16 setiembre 1777.
} 
"Considera el Rey muy propio del esmero con que la Academia Española desempeña las delicadas obligaciones de su instituto la idea de establecer los Premios anuales para promover el estudio de la Elocuencia y de la Poesía, y viene Su Majestad muy gustoso en permitir se impriman y se fijen en las Capitales del Reino carteles en que prescribiéndose las condiciones que deberán observar los que aspiren a los Premios respectivos, se propongan a oradores y poetas los correspondientes asuntos.

La elección de éstos ba parecido al Rey sumamente acertada y ha merecido todo el aprecio de Su Majestad la bien justa gratitud que en esta ocasión acredita la Academia en el obsequioso recuerdo que hace de su augusto Fundador"s.

En sesiones sucesivas de la junta de la Real Academia se fue dando cuenta de los pasos siguientes, como la impresión del cartel de los premios, el permiso solicitado a Miguel de Múzquiz para acuñar las medallas de los premios en la Casa de la Moneda, la efectiva acuñación de las mismas ( 20 de oro, 24 de plata y 40 de cobre) y la recepción de los trabajos, que eran sometidos a examen por parte de una comisión de académicos y, de acuerdo con el dictamen, preseleccionados ("reservados para examen") o rechazados ("reprobados"). En esta convocatoria llegaron a la votación final un total de 26 obras entre las de prosa (para optar al premio de elocuencia) y las de poesía. Finalmente, en la junta celebrada el 21 de julio de 1778 se otorgó un premio de poesía, pero se dejó desierto el correspondiente a la elocuencia: "Se leyeron varios papeles en prosa y se declaró que ninguno de ellos tenía mérito bastante para ser examinado y por consiguiente para adjudicarle el premio"s.

Conocemos algunos de los artículos desestimados, que quedaron archivados en la propia Real Academia. Es el caso, por ejemplo, del firmado por Alonso Arango y Sierra, capitán de infantería, gobernador militar de Oviedo y director de la Real Sociedad Económica Asturiana, que quedó inédito con el título de Elogio del Señor Don Felipe V, rey de las Españas. Y lo mismo ocurrió con el escrito por Dionisio Sáenz Galinsoga, quien, disconforme con el dictamen de los académicos, lo consideró digno de publicación, cosa que hizo por su cuenta en Segovia en la imprenta de Antonio Espinosa, en 1778, bajo el título de Idea de la verdadera gloria y grandeza humana: el muy ínclito, invicto, heroico Señor Don Felipe V, el Animoso?.

\footnotetext{
"ARAE. Actas, 25 setiembre 1777.

"ARAE. Actas, 21 julio 1778.

'ARAE. Plemios, 1778 (AGUILAR PINAL, F.: Bibliografia..., t. I, n² 2126 y t. VIL, $\mathrm{n}^{\circ} 2531$ y 2533 ). Sobre las vicisitudes del concurso de 1778 , cf. RODRIGUEZ SÁNCHEZ DE LEÓN, M. J.: "Los premios de la Academia Española en el siglo XVIII y la estética de la Época", Boletín de la Real Academia Española, vol. LXVII (1987), pp. 395-425.
} 
Dado el negativo resultado, la Academia volvió a convocar el concurso ese mismo año de 1778: "Se trató de la proposición de asuntos para los premios del año que viene y se acordó proponer para la poesía la toma de Granada por los Reyes Católicos y para la elocuencia repetir el elogio del Señor Don Felipe V"'. Esta vez el éxito coronó la empresa y el 19 de junio de 1779 se concedieron un primer y un segundo premio de elocuencia, aunque los pliegos no se abrieron hasta la junta siguiente, en cuyo transcurso se hicieron públicos los nombres de los galardonados?.

El primer premio recayó en José de Viera y Clavijo, el conocido ilustrado tinerfeño, que llegaría a ser director de la Sociedad Económica de Amigos del País de Las Palmas y que figura en el opúsculo con los títulos de académico de la Historia y de "historiógrafo de las Islas de Canaria"1". El segundo premio le fue concedido a Francisco Javier Conde y Oquendo, que ya antes había publicado un sermón pronunciado en la Catedral de La Habana y que aparece con el título de prebendado de la catedral de Puebla de los Angeles en el virreinato de Nueva España ${ }^{11}$. Ambos textos fueron editados el mismo año por Joaquín de Ibarra ${ }^{12}$.

Hay que señalar, por último, que los discursos citados no fueron los únicos publicados en fechas tardías. A tal efecto, hay que mencionar también el firmado por Manuel de Aguirre, el "Militar Ingenuo", y el pronunciado por Ramón Lázaro de Dou y Bassols en la Universidad de Cervera con ocasión del centenario del nacimiento de Felipe $\mathrm{V}$. Ambos reúnen sobrados méritos para su consideración y estudio, aunque aquí nos limitaremos a comentar tan sólo los elogios premiados

\footnotetext{
"ARAE. Actas, 25 agosto 1778.

'ARAE. Actas, 19 y 22 junio 1779.

"Sobre José de Viera y Clavijo, la bibliografia es muy abundante, por lo que vamos a limitarnos a citar los títulos esenciales: ROMEU PALAZUELOS, E.: Biografia de Viera y Clavijo a través de sis obras, Santa Cruz de Tenerife, 1991; MILLARES CARLO, A. y HERNÁNDEZ SUÁREZ, M.: Biobibliografía de escritores canarios (siglos XVI, XVII y XVIII), Las Palmas de Gran Canaria, 1992, t. VI; y GALVÁN GONZÁLEZ, V:: La obra literaria de José de Viera y Clavijo; Las Palmas de Gran Canaria, 1999.

"Francisco Javier Conde y Oquendo habia nacido en La Habana en 1733, cursando estudios con los jesuitas primero y más tarde en la Universidad de San Jerónimo, donde se doctoró en teología. Ordenado sacerdote en 1775 se trasladó a España, donde obtuvo numerosos honores como eclesiástico distinguido. En 1779 es prebendado (tal como figura en la portada del Elogio) y en 1796 canónigo de la catedral de Puebla de los Angeles en México.

${ }^{12}$ Además de la primera edición de Ibarra, Conde Oquendo publicó la obra también en México en 1785. Posteriormente fueron incluidas en la Colección de las Obras de Eloqüencia y de Poesía premiadas por la Real Academia Española, Madrid, Viuda de lbarra, 1799, Parte Primera, pp. 1-52 y 5384 , respectivamente. El opúsculo de Viera y Clavijo fue traducido al francés en 1780 por $M$. Bongars, capitán de infanteria, con el título de Eloge de Philippe V Roi d'Espagne qui a remporté le Premier Prix d'Eloquence à l'Académie Royale Espagnole, París, Demonville, 1780 (AGUILAR PIÑAL, F: Bibliografía..., t. VIIl, n' 3267. Cf. asimismo ROMEU PALAZUELOS, E.: "El elogio de Felipe V, de Viera y Clavijo, y su traducción al francés", La Tarde, 17 abril 1959). De la edición original de ambos discursos existen numerosas copias. Nosotros hemos utilizado el ejemplar custodiado por El Museo Canario de Las Palmas de Gran Canaria, gracias a los buenos oficios de Don Jesús Bombín $(+)$ y de Don Juan Gómez Pamo, a quienes deseamos expresar nuestro más sincero agradecimiento.
} 
por la Real Acadenia, dejando el resto para una ocasión propicia que permita un análisis sustantivo de cada uno de ellos separadamente ${ }^{13}$.

Los académicos no se equivocaron a la hora de ordenar los galardones, pues el texto de Viera posee una superior calidad literaria y un contenido más preciso y sustancioso, aparte de resultar más extenso (48 páginas frente a sólo 30 ) que el de su contrincante. Por esta razón, y por la similitud de sus juicios, hemos creído preferible presentar primero el discurso de Viera y señalar después los matices que añade el de Conde, pues el elemento más distintivo del prebendado de Puebla es su mayor utilización de recursos retóricos y de alusiones a la mitología y a la historia clásica, es decir una cuestión de estilo ${ }^{14}$.

Como buen historiador, Viera enmarca la actuación de Felipe $V$ dentro de la trayectoria de España durante los tiempos modernos. Asi, establece que para hacer el elogio del monarca "sería preciso repasar tres siglos de los anales de España, los de su rápido engrandecimiento, los de su decadencia asombrosa, que aquel mismo engrandecimiento produjo, y los de su feliz restauración, que no se debió sino a la misma decadencia del Estado". Y a continuación propone una síntesis de la historia moderna hispana al final de la cual aparece Felipe de Anjou, cuya misión habría sido la de "restablecer la Monarquía a la elevada cumbre de su antiguo esplendor". Una interpretación que puede suscribirse en sus líneas generales y que reivindica la figura de Felipe $\mathrm{V}$ como el verdadero restaurador, después del declive seiscentista, de la vieja grandeza de España.

A continuación, parece preciso dejar bien sentada la legitimidad del primer Borbón para ocupar el trono español. Así, se alaba la decisión de Carlos II, que, enfrentado a la cuestión sucesoria, supo encontrar la solución más justa:

"La voz de los pueblos, el dictamen de los publicistas, el voto de los Grandes, la decisión de Inocencio XIl, el interés de conservar entera la Monarquía, las leyes fundamentales del Reino, todo hablaba a favor de

\footnotetext{
${ }^{13}$ AGUIRRE, Manuel de: Idea de un principe justo o bien Elogio de Fetipe $V$ que sería publicado en el Correo de Madrid, volumen II, números 145-149 (AGUILAR PIÑAL, F: Bibliografia..., t. 1, n 431); LAZZARO DE DOUY BASSOLS, R.: In anniversario Philippi $V$ (impreso en Barcelona por Francisco de Suria). Biblioteca del Monasterio del Escorial, 43-V-13; y Biblioteca de Cataluña, 92-4 C. 9. (AGUILAR PIÑAL, F.: Bibliografia $\ldots$, t. III, $n^{\circ} 823$ ). Algún otro elogio quedó asimismo manuscrito, como el firmado por Francisco Méndez Alonso, vecino de Ocaña, y dedicado a Campomanes que presenta prácticamente el mismo título que el del "Militar Ingenuo": Idea de un príncipe justo o bien Elogio de Felipe V Rey de España, primero de la familia de Borbón, que figura en el Archivo Histórico Nacional. Consejos, Legajo 5552 (AGUILAR PIÑAL, F: Bibliografia..., t. V, $n^{\circ} 4640$ ).

id Sobre Felipe V, cf. las recientes síntesis de la Historia de España de Ramón Menéndez Pidal, vols. XXVIII, XXIX-1 y XXIX-2, Madrid, 1993-1996; KAMEN, H.: Felipe V El rey que reinó dos veces, Madrid, 2000; y ALFONSO MOLA, M. y MARTÍNEZ SHAW, C.: Felipe V, Madrid, 2001, que inciuye un balance de las distintas valoraciones de la figura del monarca en pp. 7-20.
} 
María Teresa de Austria, hermana del mismo Carlos II y mujer de Luis XIV, todo Ilamaba al trono de España a Felipe, Duque de Anjou".

La llegada de Felipe a España, ya como legítimo soberano, se hace bajo los mejores auspicios. Presenta ahora Viera en dos argumentos principales, la hermosa apariencia física del joven monarca y la continuidad con la dinastía de los Austrias. En el primer caso, "los dotes y gracias naturales de Felipe, su fisonomía amable, su gallardo cuerpo, su edad florida de diez y siete años, sus modales acompañadas de dignidad, dulzura y benevolencia, todo contribuyó para que se ganase el concepto de la Nación y para que esta formase las más lisonjeras esperanzas de su gobierno". En el segundo caso, "justificó el nuevo Monarca esta opinión pública desde los principios, mostrando bien unidas en su persona todas las heroicas prendas de los Reyes Austríacos de su nombre. Hermoso como el Primer Felipe, pero más varonil; prudente como el Segundo, pero más humano; piadoso como el Tercero, pero más entendido; grande como el Cuarto, pero más feliz".

Dedica Viera una buena parte de su discurso a trazar la historia de la guerra de Sucesión. En primer lugar se ocupa de los orígenes del conflicto, que se sitúan naturalmente en el plano de la política internacional, para después pasar a explicar su carácter de guerra civil, la adhesión de algunos en el interior del reino a la causa del archiduque:

\begin{abstract}
"¿Y sería muy extraño que tan general y deshecho torbellino arrebatase en pos de sí algunos Españoles, en quienes dominaba el espíritu de partido? ¿Las causas morales no han de obrar? El respeto habitual a la Casa de Austria, la inveterada antipatía al nombre francés, la preocupación nacional, el fanatismo de la política, los resentimientos privados, el halagüeño influjo, el problema de la sucesión, la incertidumbre de los sucesos...". Una excelente recapitulación de motivaciones donde se dan cita casi todas las que han manejado posteriormente los historiadores: la fidelidad a la dinastía de los Austrias, la animadversión hacia la Francia de Luis XIV, los sentimientos protonacionales, el juego de las facciones políticas.
\end{abstract}

A continuación el ilustrado canario expone con la misma competencia la historia militar del conflicto. Sin embargo, aún más interesante resulta la explicación que, con soberbia penetración psicológica, da al despertar de la "pasión marcial" del monarca:

"E] carácter de Felipe V, en el apacible silencio de la Corte, era inclinado a la calma de los sentidos y a la melancolía; su indole era de un Príncipe modesto, blando, naturalmente timorato, escrupuloso, taciturno y menos inclinado a gobernar con imperio que con consejo y dirección. De aquí era que necesitaba su alma tranquila de fuertes sacudimientos y grandes ocasiones para enardecerse y desplegar toda su impetuosidad y ener- 
gía; y nada había en el mundo que ocasionase en su pecho esta conmoción sino el estruendo de la guerra. Al desbocarse los caballos de Marte era cuando afirmaba sus manos en las riendas con más gusto; su corazón recogía entonces todos sus espíritus; entonces era otro hombre, entonces era cuando merecía el epíteto con que sus ejércitos y las Naciones le aclamaron, entonces era Felipe el Animoso".

Terminada la guerra, Felipe $V$ puede entregarse a la tarea de la reconstrucción de la Monarquía. Viera, que omite toda referencia a los decretos de Nueva Planta de la Corona de Aragón y que, con la excusa de dejar atrás el doloroso periodo bélico, dedica tan sólo dos insignificantes renglones al tratado de Utrecht ("que aseguró la España y la América a Felipe, a costa de algunos sacrificios y cesiones hechas a los aliados"), ofrece enseguida una perfecta síntesis de las principales líneas de la labor de gobierno del soberano: “Con la paz aumentará Felipe la población, favorecerá la agricultura, promoverá las artes, protegerá el comercio, perfeccionará el gobierno, coronará las letras, atraerá las bendiciones de la opulencia y restablecerá en Europa la antigua consideración nacional de nuestra España".

Sin embargo, antes de pasar a concretar esta declaración general, Viera presenta una serie de sucintos retratos de algunos personajes de la Corte. Empezando por la reina María Luisa Gabriela, evocada en ocasión de su muerte: "una Reina de veinte y cinco años, cuya feliz fecundidad había enriquecido la Monarquía con dos Príncipes, que fueron después sus Reyes, Luis y Fernando, y cuya discreción varonil había contribuido mucho a la conservación de la diadema en la cabeza de su esposo". Y siguiendo con la princesa de los Ursinos, "valida despótica de la Reina, mujer de manejos políticos y sublimes pensamientos, instruida, elocuente, celosa del servicio de sus Soberanos, y aun más celosa de su favor. Este retrato rcalista y agridulce precede al de Isabel Farnesio, "Princesa memorable, de espíritu superior, adomada de un alma en todo grande y de un entendimiento todo luces", que resulta exccsivamente halagador, como no podía dejar de serlo tratándose de la "madre Augusta de nuestro Carlos III".

Ahora llega el turno de las medidas concretas de gobiemo. Por un lado, la reorganización de la Hacienda, a cargo de Jean Orry ("célebre, laborioso, pero detestado"). Por otro, el fomento de la economía, a través de las leyes y reglamentos promulgados "para favorecer la agricultura, fondo de las verdaderas riquezas, para promover la industria que hace la vida grata, para animar el comercio que la hace cómoda, para multiplicar la población que la hace feliz". Y a renglón seguido, la preocupación por la educación (mediante la fundación del Real Seminario de Nobles de Madrid y de la Academia de Guardiamarinas de Cádiz), por la industria (mediante la creación de las Reales Fábricas de Tapices y de Cristales), por las artes (mediante la construcción de los palacios de Madrid y La Granja y la convocatoria de la Junta preparatoria de la Academia de San 
Fernando) y por las letras (mediante la creación de la Real Biblioteca y de las Reales Academias de la Lengua, de la Historia y Médica Matritense).

Mención especial merece, por último, el esfuerzo de restauración militar, que había llevado al ejército español a contar con "más de cien mil hombres de buena tropa", y naval, que había permitido a la Armada alcanzar los "setenta navíos de guerra". Es la ocasión de trazar un ajustado retrato de otro político clave del reinado, Julio Alberoni, "un hombre nuevo, pero extraordinario, audaz, turbulento, lleno de una imaginación ardiente y de un ingenio vasto, a quien la fortuna caprichosa había querido elevar de lo más humilde a las mayores dignidades para abandonarle después en lo más remontado de sus vuelos". Una valoración más equilibrada que aquellas que olvidan sus talentos para insistir exclusivamente en su fracaso final.

Capítulo aparte ocupa la abdicación del monarca en su hijo Luis. Situándose al margen de las diferentes interpretaciones que se han dado a tan insólita resolución, las que aceptan la razón confesada (deseo de cuidar de la salvación del alma), las que insinúan otra inconfesable (la ambición de aspirar a la Corona de Francia) o las que se pronuncian por la más plausible (el anhelo de gozar de una vida retirada), Viera se inclina por una renuncia motivada por el amor hacia su primogénito, al tiempo que establece un paralelo (por otra parte previsible) con el otro rey español igualmente alejado voluntariamente del trono, Carlos I:

"Carlos V, espléndido, esparcido, ostentoso; Feipe V, franco, moderado, modesto. Carlos retirándose porque la fortuna le dejaba; Felipe retirándose porque él despreciaba la fortuna; y con todo eso, Carlos se retiró a un Convento para vivir como religioso, y Felipe a un Palacio para morir como Príncipe".

Ahora bien, si ya con esta frase Viera se acerca a la motivación más probable, la bucólica descripción de la vida del rey en La Granja parece poner bien de manifiesto que tal era la convicción más arraigada del ilustrado canario:

"Una impresión profunda, un respeto sagrado y delicioso se apodera de nuestra imaginación cuando consideramos a Felipe de Borbón, a este héroe que había ocupado todas las cien lenguas de la fama, en el retiro de Balsaín y San Ildefonso, en el silencio del bosque y escarpados peñascos del Paular; lejos del bullicio de la Corte y del mundo, del peso de las armas y de la Corona, Rey de sí mismo, empleado en dirigir el cultivo y riego de los amenos jardines y vergeles de aquel Sitio, inagen risueña que le traia a la memoria sin cesar los de Versalles, donde en la primavera de su edad había gustado los primeros y únicos días agradables de la vida".

La segunda mitad del reinado la resuelve Viera con extrema brevedad, dando cuenta apenas de las incidencias bélicas ocurridas tanto en Europa como en 
America, antes de llegar al desenlace y a una consideración final de la figura y los hechos del soberano. Así, entre sus virtudes privadas destaca, por un lado, la castidad y el espíritu religioso (cualidad esta última más valorada por sus coetáneos que por los historiadores posteriores, que siempre le reprocharon sus excesivos escrúpulos morales) y, por otro, su natural afectuoso, que le hizo ser un buen esposo, que, dicho al paso, tuvo como consortes a dos mujeres ejemplares, y un buen padre de familia, tal como se refleja en el famoso cuadro de Michel Van Loo. Entre sus virtudes públicas, su espíritu animoso, su talante guerrero cuando hizo falta, su sentido de la moderación y de la justicia, su amor a las artes y las letras:

"Felipe V fue un Príncipe firme y animoso, sin embargo de su natural blando y tranquilo; intrépido y guerrero, sin embargo de su corazón tierno y amoroso; grande en las desgracias, sin embargo del desprecio con que miraba las grandezas; amante de las letras y de las artes, sin embargo de su índole belicosa. Fue un Rey lleno de candor, moderación, benignidad, bondad y justicia; un Rey casto, verdaderamente católico, pío, timorato, celoso de la pureza de la religión, de sus ministros y de su culto; en suma un heredero de la sangre y de la piedad de sus abuelos, San Fernando y San Luis. Fue un esposo feliz, y mil veces feliz en haber tenido por mujeres a dos verdaderas heroinas, que tiernamente amadas, comunicaron fuerza y energía a su carácter y ardieron en continuo celo de su reputación. En fin, fue un padre el más dichoso, cuyos méritos quiso coronar el cielo desde la tierra, concediéndole unos hijos tan humanos, $\tan$ respetables, $\tan$ benéficos, tan amantes de la Nación; unos hijos y nietos que han sido y serán siempre las delicias de los Españoles, la honra de los Borbones y la vanidad del género humano".

Repitiendo el esquema de Viera, comienza Conde su discurso dividiendo su reinado en una época de guerra y en otra de paz, con un prólogo dedicado a resaltar la estirpe de Felipe (en la confluencia de las casas de Austria y de Borbón) y a subrayar la esmerada educación recibida gracias a los buenos oficios de Fenelon y Fleury, considerado el primero como Jenofonte de Francia (por su Telémaco comparable a la Ciropedia) y el segundo como Tucídides de la Iglesia (por su Historia del Cristianismo parangonable con la Historia de la Guerra del Peloponeso).

La legitimidad de la causa de Felipe no ofrece ninguna duda al orador. Carlos II obra en conciencia al otorgar testamento en favor del duque de Anjou, de acuerdo con lo que disponen las leyes sucesorias del reino. En efecto, "la muerte del Augusto Testador confirma su última voluntad; la parte acepta su institución; las leyes fundamentales del reino la protegen y el consentimiento universal de los pueblos, verdadero origen de esas leyes, pone por aclamación el cetro de España en manos de Felipe".

La guerra, desencadenada por la Alianza de La Haya, que "atiza el furor republicano y los celos del Norte y Mediodía" (es decir Holanda, Inglaterra y Austria), 
pone a prueba las virtudes militares del soberano, que no dirige la contienda desde la comodidad de su palacio, sino que se pone al frente de sus tropas: "Admire quien quisiere que un príncipe joven al estrenar su espada haga de soldado y no de rey, y que al igual que la tropa soporte el calor, el frío, la hambre, sed, vigilias y demás trabajos recios de la milicia; que haga tienda de un carro, coma sobre un timbal y duerma sobre montones de armas y cadáveres; que haciendo cara a toda suerte de peligros, reconozca en persona las trincheras, dirija los ataques y corrija las lineas a sus Ingenieros; que se ponga al tiro del cañón enemigo; que se mezcle en lo más vivo de la acción y penetre hasta el centro del fuego".

Surge así la leyenda del Animoso, que supo imponerse al conjunto de los infortunios que jalonaron los primeros años de la guerra con la mayor serenidad, confiado en el justo fundamento de sus derechos:

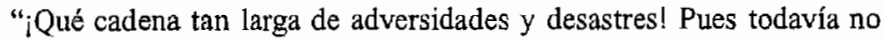
pudo arrastrar el corazón de Felipe ni arredrarle en su propósito; antes pareció que los mismos reveses de la fortuna le infundían nuevo vigor y aliento para mantenerse firme contra los balances del Trono, únicamente apoyado en la justicia de su causa, la protección del Dios de los ejércitos, su espada y las de sus invictos españoles".

Conde se detiene a continuación en la descripción de la actitud del rey tras la victoria frente a sus enemigos. Sin embargo, más que un análisis ponderado, se entrega a una retórica celebración de su clemencia (como no podía ser menos en un soberano que sólo quería ser el padre de su patria, como Tito), de modo que, salvo una alusión a la represión de Játiva, el resto se resuelve en una serie de alabanzas hacia su conducta, tanto en Zaragoza ("el mismo que poco antes mandó demoler a Xátiva, ahora publica una amnistía y hace venir allí a su amabilísima consorte y recién nacido príncipe, para que la terneza de su amor ganase los corazones, que nunca se entregan al filo de la espada"), como en Barcelona:

"Desplegó toda su humanidad y mansedumbre, rasgó por su mano los procesos y despachó tantos indultos que en vez de anegar las plazas en sangre bañó de alegría las calles y las casas, y salió el reino como a una nueva vida de entre las fauces de la muerte y de la infamia, peor que la muerte misma".

En resumen, Felipe $V$ se comportó como un rey que "nada sintió tanto al ceñir la Corona como el no poder gobernar a los Españoles sin vencerlos con los Españoles mismos". Porque los hechos posteriores mostraron la completa hispanización del monarca, su amor por el pueblo al que había sido destinado a gobernar:

"Felipe $V$ no vacila, ni por las sugestiones del abuelo ni por los encantos del país ni por el apego natural a la herencia de sus mayores. Resueltamente dice delante de su Corte y Ministros de las extranjeras que 
no cambiaría por la Monarquía universal la más pequeña parte de la España. Españoles, vuesto Rey os ama, y con amor de preferencia sobre todos los pueblos del mundo. Un rey de otra gente, y de otra tribu, nacido en otro cielo, y educado por otras manos, entre costumbres y modales muy diferentes de las vuestras, ha mudado de carácter y de patria y se ha dejado atar a una nación extraña y de muchos ticmpos enemiga, con nudos más estrechos que los de la carne y la sangre. ¿Qué vasallos han recibido de parte de un monarca nacional testimonios menos falibles de su amor?"

Tras una justa descalificación de la paz de Utrecht ("si es que merece este nombre una paz solapada, que restañó la sangre sin cerrar las heridas") y un elogio, tal vez excesivo pero no tan lejos de la realidad como ha argumentado una historiografía adversa hacia su persona, del barón de Ripperdá, "un genio superior" que permitió al rey negociar "con honestas condiciones la celebrada paz de Viena y aquel famoso tratado de comercio (se refiere a la creación de la Compañía de Ostende) que sacó fuera de sí a las potencias marítimas".

Como hiciese Viera, también Conde se explaya ahora en los logros del gobierno de Felipe V, referidos tanto al adelanto de la economía como a la expansión de la cultura, aunque de nuevo el nivel de concreción en estas materias es menor que en el caso de su adversario en el certamen:

"Felipe conoce la importancia de estas máximas y pone todo su esmero en la educación e industria, la protección del labrador y mercader, minoración de tributos y derechos, remisión total de contribuciones y servicios, seguridad de la navegación y los caminos, equidad en las aduanas y las puertas (...) Nuevas leyes y establecimientos, nuevas fábricas y telares, nuevas máquinas y macstros, nuevos caminos y canales, correo marítimo, comercio libre, revolución general del Estado: todo se ha puesto en acción y movimiento; aquello va saliendo de la nada y esto caminando a su perfección. Escuelas y Academias restauran la Milicia, las letras y la lengua; Seminarios y Monasterios educan la nobleza de ambos sexos; Hospicios y Sociedades destierran el ocio, ensalzan los oficios y honran los oficiales".

Así aparece Felipe V, en la mente del orador, como el restaurador de las viejas glorias nacionales, después de un periodo de decadencia: "Comparen este siglo con el antecedente y confiesen con sinceridad y acciones de gracias cuánto es lo que deben a la Augusta Casa de Borbón". Una idea que se repite más adelante: "Felipe, después de haber peleado y vencido a las naciones más cultas y belicosas de Europa, después de haber puesto en su mayor auge los dos Mundos de su obediencia, y a punto de recobrar las armas, letras y comercio aquel esplendor y prepotencia que nadie las disputó en el siglo diez y seis, siglo de oro muy parecido al de Augusto..., (la muerte) fue tan pronta que sólo le dio lugar de inclinar la cabeza sobre el amado seno de su tierna esposa". 
La abdicación también en este caso ocupa su lugar en el discurso. Conde defiende la decisión de Felipe contra las opiniones que la atribuyen a un cálculo político y acepta como motivo el deseo de monarca de llevar una vida recoleta en favor de la salvación de su alma, de buscar "la soledad de Balsaín para aprender a morir". Y, del mismo modo, la delicada cuestión constitucional de la reasunción de la Corona y la probablemente sincera resistencia del soberano, encuentran la interpretación más optimista: "La fidelísima esposa le ruega, los ministros le arguyen, los pueblos todos le aclaman, y Felipe no se mueve sino cuando le ponen por delante a Dios, la conciencia, el peligro de una tutela y los perjuicios del Estado".

No le queda al prebendado de Puebla de los Angeles sino redactar el párrafo conclusivo. Sin embargo, no encontramos aquí un resumen de las virtudes o de los logros del monarca, sino una alusión retórica a la transmisión de sus cualidades a sus descendientes, los soberanos españoles de la "augusta rama de Borbones-Austríacos", que cumplirán a la perfección, como herederos de la doble tradición hispana y francesa, la también doble misión (propia de una monarquía cristiana e ilustrada) de defender la religión católica y de velar por la felicidad de sus súbditos: "Reyes al fin Católicos y Cristianísimos, dignos sucesores de San Fernando y de San Luis, ligados por medio de una santa alianza, para exaltar el nombre de Dios y hacer felices a los hombres".

Tras su lectura, puede constatarse que los dos elogios presentan más similitudes que diferencias. Ambos reafirman la legitimidad de los derechos de Felipe $\mathrm{V}$ a la Corona de España, insisten en la continuidad con la casa anteriormente reinante, subrayan los éxitos del Animoso en el transcurso de la guerra de Sucesión, justifican la abdicación y subsiguiente vuelta al trono, realzan las cualidades positivas de su vida privada (benignidad, castidad y religiosidad), defienden la acertada elección de sus ministros (incluyendo Viera al abate Alberoni y Conde al barón de Ripperdá, los más controvertidos del periodo y los más denostados por los historiadores posteriores) y asientan finalmente en el haber del primer Borbón la restauración de la antigua grandeza de España y su Imperio.

En definitiva, los dos elogios están muy próximos a la valoración del reinado que hoy parece imponerse, pueden figurar a justo título como piezas del fundamentado proceso de rehabilitación de la época de Felipe $V$ que actualmente se halla en curso. En efecto, para los contemporáneos, Felipe V había sido sin duda el rey que había puesto un dique a la decadencia y había conseguido restablecer el poder militar, la economía y la vida cultural de la nación. Sin duda, estaban más cerca de la realidad tal como hoy se nos revela que gran parte de la historiografia posterior, al señalar a Felipe $V$ como el primer monarca reformista, como el primer monarca ilustrado. 